\title{
Vibroacustic microvibrations enhance kidney blood supply, glomerular filtration and glutathione peroxidase activity in spontaneously hypertensive rats
}

\author{
Zoran Miloradović, Nevena Mihailović-Stanojević, Đurđica Jovović, Milan Ivanov, Una J. \\ Vajić, Danijela Karanović and Jelica Grujić Milanović \\ Institute for Medical Research, University of Belgrade, Belgrade, Serbia
}

\begin{abstract}
Limited numbers of studies include research of microvibration therapy in experimental models. We examined effects of chronic vibroacustic-microvibration treatment on haemodynamics and anti-oxidative defense in experimental hypertension. Study was performed on chronically treated hypertensive and normotensive Wistar rats. Mean arterial pressure (MAP), cardiac output (CO), renal blood flow (RBF), glomerular filtration and activity of anti-oxidative enzymes were determined after three weeks treatment. Vibroacustic treatment had no influence on MAP and $\mathrm{CO}$, but RBF was increased in both groups of treated rats. Additionally, vibroacustic treatment enhanced diuresis and increased glomerular filtration in hypertensive rats. Glutathione peroxidase (GSH-Px) activity was elevated in both treated rat strains, but activity of superoxide dismutase was unchanged. We conclude that microvibration treatment doesn't ameliorate hypertension but improves renal blood supply (trough diminished renal vascular resistance), glomerular filtration, diuresis, and enhances glutathione dependent anti-oxidant defense with more important beneficials in hypertensive animals.
\end{abstract}

Key words: Vibroacustic microvibrations - Experimental hypertension - Oxidative stress

\section{Introduction}

Vibroacoustic may be defined as the process of propagation of sound vibrations through the body, considering that body of animals and humans is consists of cells that naturally vibrate in sound frequencies (Boyd-Brewer and McCaffrey 2004). In the middle of the last century, Rohracher (1946) claimed firstly that the entire surface of the human and homothermic animal body exhibits continuous microvibrations with frequency $7-13 \mathrm{~Hz}$ due to muscular and cardiac activity. During the last 30 years vibroacoustic therapy is used in clinical treatment (sedative music and pulsed, sinusoidal low frequency tones 20-70 Hz, played through a bed or chair). There has been a substantial amount of research investigating vibratory

Correspondence to: Zoran Miloradović, Institute for Medical Research, Dr Subotića 4, University of Belgrade, 11129 Belgrade, PO Box 102, Serbia

E-mail: zokim@imi.bg.ac.rs sensitivity in subjects including infrasound, ultrasound, noise and music. Clinical benefits include: pain reduction, muscle relaxation, better joint and muscle flexibility, improved blood circulation and better sense of well-being (Lundeberg et al. 1988; Kerschan-Schindl et al. 2001; Sands et al. 2006). So far, most studies investigating the effect of vibration on blood flow have used frequencies common among tools used in industry which generally means 80 $\pm 100 \mathrm{~Hz}$ (Kerschan-Schindl et al. 2001). Nevertheless, there is limited number of studies included in research of vibroacustic effects on blood flow and arterial pressure as well as oxidative stress in experimental models.

Considering hypertension as one of the most prevalent and powerful contributors to cardiovascular diseases, and the spontaneously hypertensive rat (SHR) as most commonly used model for studies of human essential hypertension (Doggrell and Brown 1998), we tried to examine effects of chronic vibroacustic microvibration treatment on both haemodynamic status and anti-oxidative defense in experimental hypertension and normotension. 


\section{Materials and Methods}

\section{Animals and vibroacustic device}

The experimental protocol was approved by the Ethic Committee of the Institute for Medical Research, University of Belgrade, Serbia (No 0312-1/10). Study was done according to the Serbian National Law on Animal Welfare. It consistencies with: guidelines for animal research and principles of the European Convention for the Protection of Vertebrate Animals Used for Experimental and Other Purposes (Official Daily N. L 358/1-358/6, 1986) and Directive on the protection of animals used for scientific purposes (Directive 2010/63/EU of the European Parliament and of the Council, 2010).

Six months old male SHR and age/sex matched normotensive Wistar rats weighing about $300 \mathrm{~g}$ (bred at the Institute for Medical Research, University of Belgrade, Serbia) were used. The rats were housed in polyethylene cages in temperature and humidity controlled rooms on a twelve-hour light-dark cycle, with free access to food and water.

For animal treatment we used vibroacustic device Vitafon-T (gift from FIP-Komerc Belgrade, Serbia) in variable frequency range of $30-4500 \mathrm{~Hz}$, amplitude range $2.8-5.4 \mu \mathrm{m}$, impulse modulation $05-1.2 \mathrm{~s}$, as specified on device manual. This mod (No. 2) is recommended by manufacture as beneficial in human hypertension.

\section{Experimental groups and protocols}

In all animals, systolic blood pressure and heart rate were indirectly measured using a tail-cuff pneumatic pulse detector and a direct recorder (Physiograph Four, Narco Bio-System, Houston, TX, USA). Two separate baseline determinations of body mass and systolic blood pressure were made in a span of 4 days and then rats were divided into following groups:

- Wistar C - control normotensive rats $(n=9)$

- Wistar $\mathrm{V}$ - vibroacustic treated normotensive rats $(n=$ 12)

- SH C - control hypertensive rats $(n=10)$

- SH V - vibroacustic treated hypertensive rats $(n=11)$. Conscious animals were treated with vibroacustic device 10 minutes per day during 3 weeks. The first vibroacustic transmitter was placed ventrally (on the abdomen surface) and the second dorsally (upon the kidney area). Transmiters were fixed to the animal body by elastic strips. Control animals were fitted only with elastic strips (at the same treatment period). After three weeks treatment, all animals had placed in metabolic cages for 24 hours urine collection, treated again and than preceded to the haemodynamic measurement.

\section{Haemodynamic measurements}

Haemodynamic studies were performed in anesthetized (pentobarbital, $35 \mathrm{mg} / \mathrm{kg}$ i.p.) adult male spontaneously hypertensive rats (SHR), and age/sex match normotensive Wistar rats. Mean arterial pressure (MAP) and heart rate (HR) were measured through a femoral artery catheter (PE-50, ClayAdams Parsippany, NY, USA), connected to the physiological data acquisition system (9800TCR Cardiomax III-TCR, Columbus, OH, USA). Cardiac output (CO) was measured by thermodilution. A jugular vein was cannulated with polyethylene tubing PE-50. Thermo sensor was placed in a left carotid artery and coupled to the Cardiomax III. The second thermocouple was placed in cold saline. Than, cold saline $(0.2$ $\mathrm{ml}$ ) was administered through the jugular vein and mean arterial pressure (MAP) and CO were recorded. Total peripheral vascular resistance (TPVR) was calculated by dividing MAP $(\mathrm{mmHg})$ with $\mathrm{CO}(\mathrm{ml} / \mathrm{min} \mathrm{kg}$; assuming that mean right atrial pressure is zero) and expressed as $\mathrm{mmHg} \cdot \mathrm{min} \cdot \mathrm{kg} / \mathrm{ml}$.

For the renal blood flow (RBF) measurement, after abdominal incision the left renal artery was gently separated. An ultrasonic flow probe (1RB, internal diameter $=1 \mathrm{~mm}$ ) was placed around the artery, and connected to the Transonic T106 Small Animal Flowmeter (Transonic System Inc., Ithaca, NY, USA). Renal vascular resistance (RVR) was calculated by dividing MAP $(\mathrm{mm} \mathrm{Hg})$ with $\mathrm{RBF}(\mathrm{ml} / \mathrm{min} \mathrm{kg}$ ) and expressed as $\mathrm{mmHg} \cdot \mathrm{min} \cdot \mathrm{kg} / \mathrm{ml}$.

\section{Biochemical measurements}

At the end of the haemodynamic study blood samples were taken for determination of creatinine $\left(\mathrm{P}_{\mathrm{Cr}}\right)$ and urea $\left(\mathrm{P}_{\mathrm{U}}\right)$ in plasma, as well as erythrocyte antioxidant enzymes activity. Than, all rats were sacrificed according to the animal ethical guidelines. Lithium-heparin (Li-heparin, Sigma, USA) was used as an anticoagulant. We used previously collected urine samples for determination of creatinine $\left(\mathrm{U}_{\mathrm{Cr}}\right)$ and urea $\left(\mathrm{U}_{\mathrm{U}}\right)$ in urine. All biochemical parameters were calculated using an automatic Cobas Integra 400 plus (Hoffmann-La Roche, Germany) analyzer. Creatinine and urea clearances $\left(\mathrm{C}_{\mathrm{Cr}} ; \mathrm{C}_{\mathrm{U}}\right)$ were calculated on the basis of: $\mathrm{U}_{\mathrm{Cr}}$ and $\mathrm{U}_{\mathrm{U}}, \mathrm{P}_{\mathrm{Cr}}$ and $\mathrm{P}_{\mathrm{U}}$, urine volume and body weight, using the standard equation for clearance.

Blood samples were centrifuged at $3000 \mathrm{rpm}$ at $4^{\circ} \mathrm{C}$ for 15 minutes and erythrocytes were separated. Hemoglobin (Hb) content was estimated by the method of Drabkin and Austin (1935). Spectrophotometric analyses of erythrocyte antioxidant enzyme activities were performed with Ultrospec 3300 pro UV/Visible spectrophotometer (Amersham Biosciences Corp., USA).

Glutathione peroxidase (GSH-Px) activity was determinated according to the previously described method suggested by Paglia and Valentine (Paglia and Valentine 1967). The GSHPx activity was expressed as unit per gram of hemoglobin (U/g 

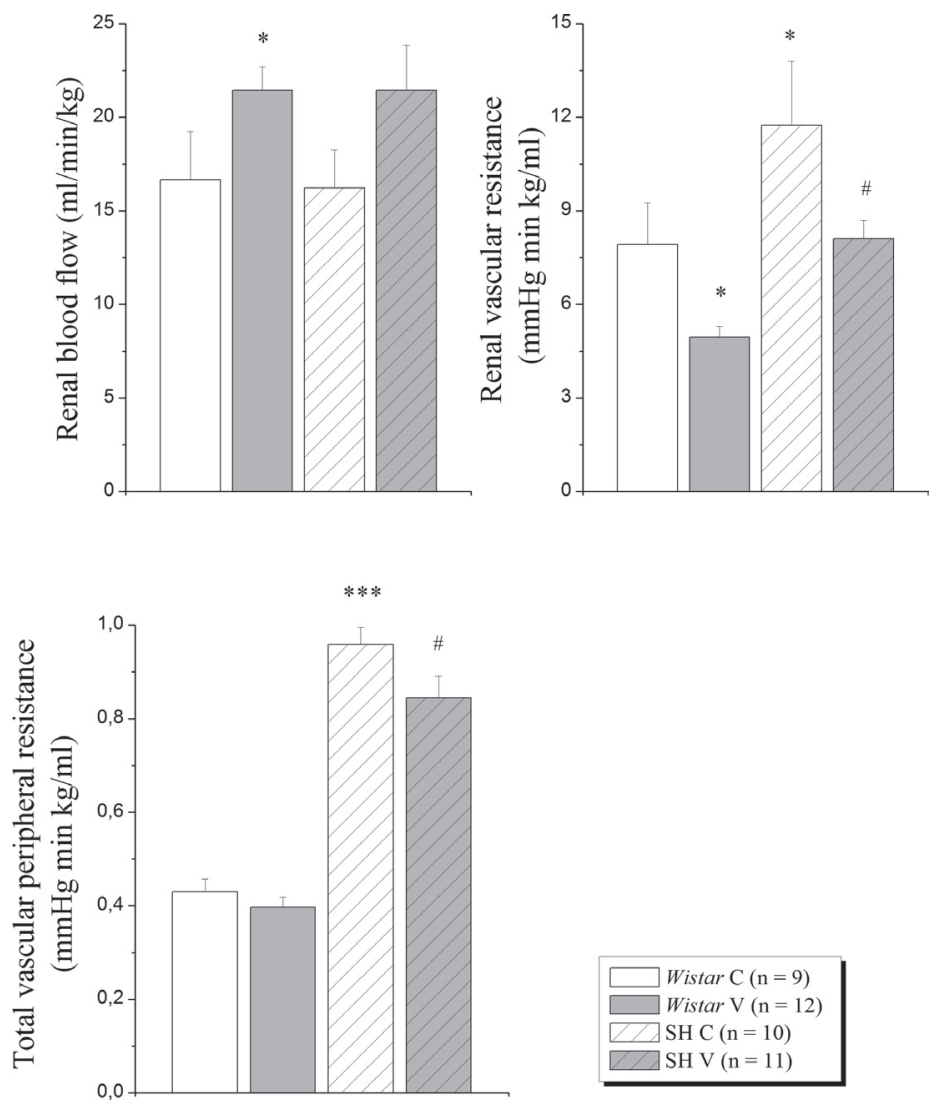

Figure 1. Renal haemodynamic parameters and total vascular peripheral resistance in experimental groups after vibroacustic treatment. Wistar $\mathrm{C}$, control normotensive rats; Wistar $\mathrm{V}$, vibroacustic treated normotensive rats; SH C, control hypertensive rats; $\mathrm{SH}$ V, vibroacustic treated hypertensive rats; ${ }^{\star} p<0.05$ vs. Wistar $\mathrm{C} ;{ }^{* * *} p<0.001$ vs. Wistar C; $\# p<0.05$ vs. SH C; $n$, number of animals.

$\mathrm{Hg}$ ). One unit of GSH-Px was defined as $\mu \mathrm{mol}$ of oxidized NADPH per minute per gram of hemoglobin.

Activity of superoxide dismutase (SOD) was measured by spectrophotometry, using previously described method of epinephrine autoxidation (Misra and Fridovich 1972) and expressed as $\mathrm{U} / \mathrm{g} \mathrm{Hb}$.

\section{Statistical analysis}

The results are shown as the mean \pm SEM. We used the singlesided Student's t-test for two-samples of equal variance (Microsoft Excel 2010) for comparison between two examined groups. There were compared control Wistar and SH groups and, on the other hand, vitaphoned groups $v s$. their respective controls. The value $p<0.05$ was considered notable.

\section{Results}

\section{Haemodynamic parameters}

Arterial blood pressure was significantly increased in SHR in comparison to Wistar rats $(p<0.001)$. Vibraphone treatment changed neither blood pressure nor heart rate in both

Table 1. Haemodynamic parameters in experimental groups after vibroacustic treatment

\begin{tabular}{lcccc}
\hline Experimental groups & $\begin{array}{c}\text { MAP } \\
(\mathrm{mm} \mathrm{Hg})\end{array}$ & $\begin{array}{c}\text { HR } \\
\text { (beat/min) }\end{array}$ & $\begin{array}{c}\text { CO } \\
(\mathrm{ml} / \mathrm{min} / \mathrm{kg})\end{array}$ & $\begin{array}{c}\text { SV } \\
(\mathrm{ml} / \mathrm{kg})\end{array}$ \\
\hline Wistar C $(n=9)$ & $101 \pm 5.11$ & $347.67 \pm 10.59$ & $233.38 \pm 13.25$ & $0.815 \pm 0.063$ \\
Wistar V $(n=12)$ & $93 \pm 6.45$ & $337.83 \pm 9.58$ & $260.28 \pm 16.77$ & $0.840 \pm 0.053$ \\
SH C $(n=10)$ & $154.6 \pm 4.82^{* * *}$ & $359.70 \pm 17.94$ & $214.63 \pm 12.73$ & $0.547 \pm 0.031^{* * *}$ \\
SH V $(n=11)$ & $161.45 \pm 5.29$ & $388.45 \pm 10.48$ & $246.40 \pm 17.85$ & $0.620 \pm 0.047$ \\
\hline
\end{tabular}

Wistar C, control normotensive rats; Wistar V, vibroacustic treated normotensive rats; SH C, control hypertensive rats; SH V, vibroacustic treated hypertensive rats; MAP, mean arterial pressure; HR, heart rate; CO, cardiac output; SV, stroke volume; ${ }^{* *} p<0.001 v s$. Wistar C; $n$, number of animals. 

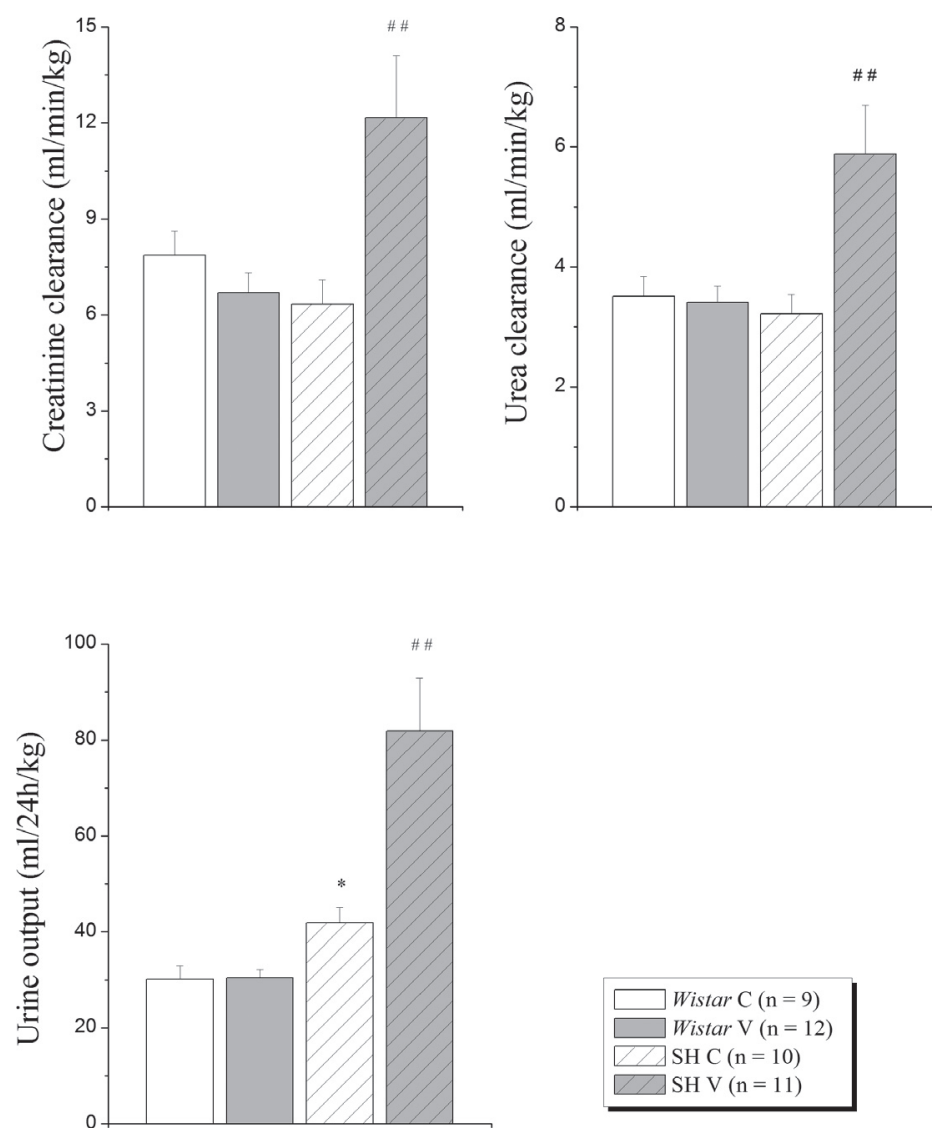

Figure 2. Creatinine/urea clearances and urine output in experimental groups after vibroacustic treatment. Wistar $\mathrm{C}$, control normotensive rats; Wistar $\mathrm{V}$, vibroacustic treated normotensive rats; $\mathrm{SH} \mathrm{C}$, control hypertensive rats; $\mathrm{SH} \mathrm{V}$, vibroacustic treated hypertensive rats; ${ }^{\star} p<0.05 v s$. Wistar C; \#\# $p<0.01$ vs. SH C; $n$, number of animals.

normotensive and hypertensive rats (Table 1). There were no differences in $\mathrm{CO}$ between the groups, while stroke volume was significantly reduced in control SHR in comparison to control Wistar rats $(p<0.001)$. Treatment with vibroacustic micro vibrations had no influence on this parameter too (Table 1).

Long-lasting hypertension was associated with increased TPVR in SHR (Figure 1) compared to normotensive rats $(p<0.001)$. Microvibrations significantly reduced TPVR in SHR ( $p<0.05)$. RBF was increased in both Wistar and SHR vibroacustic treated rats in comparison to their respective controls. This increasing was significant in normotensive animals $(p<0.05)$ and moderate in hypertensive rats. On the other hand, RVR was significantly decreased in both Wistar and SHR vibroacustic treated rats in comparison to their respective controls $(p<0.05)$, (Fig. 1).

\section{Biochemical parameters}

Urine output was increased in SHR in comparison to Wistar rats $(p<0.01)$. Vitafon-T treatment additionally enhanced diuresis in SHRs, compared to their controls $(p<0.01)$. Also, vibroacustic treatment increased glomerular filtration (expressed via both urea and creatinine clearances) in hypertensive rats $(p<0.05)$, (Fig. 2).
Activity of GSH-Px was elevated in SHR in comparison to Wistar rats $(p<0.001)$. Vibroacustic treatment additionally increase GSH-Px activity in both rat strains in comparison to their respective controls $(p<0.001$ in Wistar treated and $p<0.05$ in SHR treated rats) (Fig. 3).

Activity of SOD was diminished in SHR compared to Wistar rats $(p<0.01)$. Microvibration treatment didn't influence this activity in both rat strains (Fig. 3).

\section{Discussion}

Vibroacoustic therapy is a treatment method based on low frequency sound vibration (microvibrations). Except music therapy (Curtis et al. 1986; Chesky et al. 1996) there are very limited data related to microvibration effects on haemodynamic parameters, especially in any animal model. In this study we have used chronically-induced vibroacoustic microvibrations to evaluate their influence on cardiovascular and oxidative parameters in normotensive and hypertensive rats. Our results show that 10 minutes variable vibroacoustic microvibrations have no influence on blood pressure and heart rate in both rat strains after three weeks treatment. Boughner and Roach (1971) showed that acute treated 
carotid artery of humans failed to dilate to the low $(70 \mathrm{~Hz})$ and middle range $(160 \mathrm{~Hz})$ external vibroacustic stimulation, but did dilate to a vibration of $325 \mathrm{~Hz}$. On the other hand, considering blood pressure homeostasis, results of our study indicate that both rat strains had adaptive potential against prolonged microvibration treatment. This indicates effective both fast blood pressure control and vascular reactivity which were unaffected with microvibration stimuli. Long-lasting hypertension followed by prolonged pressure overload and progression of cardiac hypertrophy expectably diminished stroke volume in SHR (Pfeffer et al. 1982). Vitafon treatment didn't affect this deterioration, which directed us to conclude that chronic microvibrations neither induced sustained positive inotropic effect on cardiac muscle nor elicited large artery vasodilatation. This opinion is further supported by unchanged cardiac output in vibraphone-treated animals and, on the other hand, by reduced total peripheral vascular resistance in treated SHR. Besides, diminished vascular resistance implies predominantly peripheral effects of microvibrations, probably due to small artery vasodilatation. This is in accordance with Lohman et al. (2007) who suggested that short-term vibration alone significantly increased peripheral blood flow in skin, minimum of 10 minutes following intervention. Development of hypertension in SHR is characterized by elevated renal vascular resistance (Schnackenberg et al. 1998) as a reflection of marked endothelial dysfunction in renal artery vasculature. Vibroacustic treatment in our experimental design elevated blood flow and significantly reduced vascular resistance in the left renal artery of both Wistar and SHR. It was reported (Kerschan-Schindl et al. 2001) that vibrations significantly increased blood cell velocity, therefore increased a blood flow. Our study revealed this point through improved renal artery haemodynamic and enhanced kidney blood supply in both vibraphoned rat strains. These effects are more important in hypertensive animals indicating beneficial properties of vibroacustic treatment in conditions with endothlelial and renal dysfunction such as hypertension. Beside increased blood cell velocity, there is possibility (suggested by manufacture) that variable micro vibrations directed blood vessels as hydrodynamic pumps to more effective blood circulation. Further, amelioration of renal artery haemodynamics was followed by glomerular filtration increasing and enhanced urine output in SHR. There is evidence that advanced hypertension in SHR seems to start a renal vicious circle, because accentuated reductions of filtration capacity are paralleled by structural postglomerular resistance increases, apparently to maintain glomerular filtration rate by raised filtration pressure which, however, accelerates glomerular deterioration (Göthberg and Folkow 1983). By our opinion, glomerular filtration and urine output improvement in vibraphoned SHR is reflection of renal blood flow enhancement due to microvibration-induced

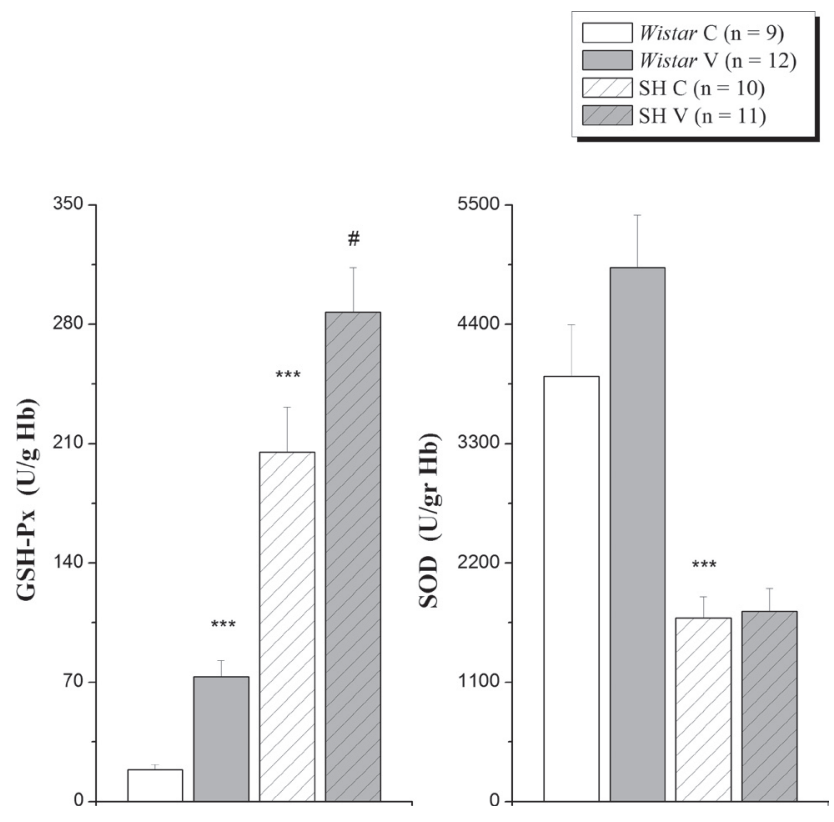

Figure 3. Activities of glutathione peroxidase (GSH-Px) and superoxide dismutase (SOD) in experimental groups after vibroacustic treatment. Wistar $\mathrm{C}$, control normotensive rats; Wistar $\mathrm{V}$, vibroacustic treated normotensive rats; $\mathrm{SH}$ C, control hypertensive rats; SH V, vibroacustic treated hypertensive rats; ${ }^{* * *} p<0.001 v s$. Wistar C; \# $p<0.05$ vs. SH C; $n$, number of animals.

increasing of blood cell velocity, as previously reported by Kerschan-Schindl et al. (2001).

Previous studies indicate that SHR, as an animal model of human essential hypertension, shows elevated RBC glutathione level as an adaptation against oxidative stress in vivo related to genetic hypertension (Yuan et al. 1996). Our results indicate that vibroacustic treatment additionally stimulates activity of GSH-Px, leading to more effective oxidative defense in this hypertensive strain. On the other hand, activity of SOD was unchanged in both vibraphoned strains in comparison to their respective controls. There is evidence that SOD activity is reduced in hypertensive patients as well as in SHR (Ito et al. 1995). Similar results we obtained in SHR in our presented study. SOD rapidly converts $\mathrm{O}_{2}^{2}$ to the less reactive $\mathrm{H}_{2} \mathrm{O}_{2}$ that is further degraded by catalase and GPx. Besides, the expression of GPx can be stimulated during excessive exposure to $\mathrm{H}_{2} \mathrm{O}_{2}$ (Erden and Bor 1984), produced either by enhanced SOD activity or by direct oxidative production from other sources (Arduini et al. 1988). Unchanged SOD activity in our experimental design suggests that $\mathrm{H}_{2} \mathrm{O}_{2}$ is originated from other sources, probably due to intensive oxygenation after microvibration treatment. On the other hand, significantly elevated GSH-Px activity in vibraphoned animals expresses potential to effectively neutralize consequences of this excessive oxygenation. 
Taken together, we can conclude that in this pioneering study (considering microvibration testing in experimental hypertension) 10 minutes daily microvibration treatment has no effect on blood pressure, but improves renal blood supply (by diminishing renal vascular resistance), glomerular filtration and diuresis, with more important role in hypertensive animals. Furthermore, it enhances glutathione-dependent antioxydative defence in SHR out of direct SOD stimulation. Relevance of these results appears as a material for further investigation, but it is reasonable to conclude that prolonged vibroacustic microvibrations have no obvious harmful effects and improve both renal haemodynamic and glomerular filtration in hypertensive rats. This could be beneficial in some pathological conditions with affected renal function such as acute and chronic kidney failure, but more pronounced preclinical studies are needed for definite conclusions.

Acknowelegements. This work was supported by Ministry of Education, Science and Technological development of Serbia (projects OI175096) and by gift of FIP-KOMERC Beograd, Serbia.

Conflict of interest. The authors declare no conflict of interest and no financial interest in the publication of this manuscript.

\section{References}

Arduini A., Mezzetti A., Porreca E., Lapenna D., DeJulia J., Marzio L., Polidoro G., Cuccurullo F. (1988): Effect of ischemia and reperfusion on antioxidant enzymes and mitochondrial inner membrane proteins in perfused rat heart. Biochim. Biophys. Acta 970, 113-121 http://dx.doi.org/10.1016/0167-4889(88)90169-3

Boughner D. R., Roach M. R. (1971): Effect of low frequency vibration on the arterial wall. Circ. Res. 29, 136-144 http://dx.doi.org/10.1161/01.RES.29.2.136

Boyd-Brewer C., McCaffrey R. (2004): Vibroacoustic sound therapy improves pain management and more. Holist. Nurs. Pract. 18, 111-118; quiz 118-119 http://dx.doi.org/10.1097/00004650-200405000-00002

Chesky K. S., Michel D. E., Kondraske G. (1996): Developing methods and techniques for scientific and medical application of music vibration. In: Music Medicine 2. (Eds. Spintge R., Dron R.), pp. 227-241, MMB, Music, St. Louis

Curtis S. L. (1986): The effect of music on pain relief and relaxation of the terminally ill. J. Music Ther. 23, 10-24 http://dx.doi.org/10.1093/jmt/23.1.10

Doggrell S. A., Brown L. (1998): Rat models of hypertension, cardiac hypertrophy and failure. Cardiovasc. Res. 39, 89-105 http://dx.doi.org/10.1016/S0008-6363(98)00076-5

Erden M., Bor N. M. (1984): Changes of reduced glutathion, glutathion reductase, and glutathione peroxidase after radiation in guinea pigs. Biochem. Med. 31, 217-227 http://dx.doi.org/10.1016/0006-2944(84)90026-7
Drabkin D. L., Austin J. H. (1935): Spectrophotometric studies II. Preparations from washed blood cells; nitric oxide hemoglobin and sulfhemoglobin. J. Biol. Chem. 112, 51-65

Göthberg G., Folkow B. (1983): Age-dependent alterations in the structurally determined vascular resistance, pre- to postglomerular resistance ratio and glomerular filtration capacity in kidneys, as studied in aging normotensive rats and spontaneously hypertensive rats. Acta Physiol. Scand. 117, 547-555 http://dx.doi.org/10.1111/j.1748-1716.1983.tb07225.x

Ito H, Torii M., Suzuki T. (1995): Decreased superoxide dismutase activity and increased superoxide anion production in cardiac hypertrophy of spontaneously hypertensive rats. Clin. Exp. Hypertens. 17, 803-816 http://dx.doi.org/10.3109/10641969509033636

Kerschan-Schindl K., Grampp S., Henk C., Resch H., Preisinger E., Fialka-Moser V., Imhof H. (2001): Whole-body vibration exercise leads to alterations in muscle blood volume. Clin. Physiol. 21, 377-382 http://dx.doi.org/10.1046/j.1365-2281.2001.00335.x

Lohman E. B. 3rd., Petrofsky J. S., Maloney-Hinds C., Betts-Schwab H., Thorpe D. (2007): The effect of whole body vibration on lower extremity skin blood flow in normal subjects. Med. Sci. Monit. 13, CR71-76

Lundeberg T., Abrahamsson P., Bondesson L., Haker E. (1988): Effect of vibratory stimulation on experimental and clinical pain. Scand. J. Rehabil. Med. 20, 149-159

Misra H. P., Fridovich I. (1972): The role of superoxide anion in the autoxidation of epinephrine and a simple assay for superoxide dismutase. J. Biol. Chem. 247, 3170-3175

Paglia D. E., Valentine W. N. (1967): Studies on the quantitative and qualitative characterization of erythrocyte glutathione peroxidase. J. Lab. Clin. Med. 70, 158-169

Pfeffer J. M., Pfeffer M. A., Mirsky I., Braunwald E. (1982): Regression of left ventricular hypertrophy and prevention of left ventricular dysfunction by captopril in the spontaneously hypertensive rat. Proc. Natl. Acad. Sci. U.S.A. 79, 3310-3314 http://dx.doi.org/10.1073/pnas.79.10.3310

Rohracher H. (1946): Einführung in die Psychologie. Urban \& Schwarzenberg, Wien

Sands W. A., McNeal J. R., Stone M. H., Russell E. M., Jemni M. (2006): Flexibility enhancement with vibration: Acute and long-term. Med. Sci. Sports Exerc. 38, 720-725 http://dx.doi.org/10.1249/01.mss.0000210204.10200.dc

Schnackenberg C. G., Welch W. J., Wilcox C. S. (1998): Normalization of blood pressure and renal vascular resistance in SHR with a membrane-permeable superoxide dismutase mimetic: role of nitric oxide. Hypertension 32, 59-64 http://dx.doi.org/10.1161/01.HYP.32.1.59

Yuan Y. V., Kitts D. D., Godin D. V. (1996): Heart and red blood cell antioxidant status and plasma lipid levels in the spontaneously hypertensive and normotensive Wistar-Kyoto rat. Can. J. Physiol. Pharmacol. 74, 290-297

Received: April 25, 2014

Final version accepted: October 1, 2014

First published online: November 14, 2014 